\title{
B vitamins to enhance treatment response to antidepressants in middle-aged and older adults: results from the B-VITAGE randomised, double-blind, placebo-controlled trial
}

Osvaldo P. Almeida, Andrew H. Ford, Varsha Hirani, Vash Singh, Frank M. vanBockxmeer, Kieran McCaul and Leon Flicker

\section{Background}

Depression is common and the efficacy of antidepressants is suboptimal. High plasma homocysteine has been consistently associated with depression, and treatment with certain $B$ vitamins demonstrably reduces its concentration.

\section{Aims}

To determine whether vitamins $B_{6}, B_{12}$ and folic acid enhance response to antidepressant treatment over 52 weeks.

\section{Method}

Randomised, double-blind, placebo-controlled trial of citalopram (20-40 g) together with $0.5 \mathrm{mg}$ of vitamin $\mathrm{B}_{12}$, $2 \mathrm{mg}$ of folic acid and $25 \mathrm{mg}$ of vitamin B6 for 52 weeks (Australian and New Zealand Clinical Trials Registry: 12609000256279). Participants were community-dwelling adults aged 50 years or over with DSM-IV-TR major depression. We measured severity of symptoms with the Montgomery-Assberg Depression Rating Scale (MADRS). The primary outcome was remission of the depressive episode after 12, 26 and 52 weeks. Secondary outcomes included reduction of MADRS scores over time and relapse of major depression after recovery by week 12 .

\section{Results}

In total, 153 people were randomised (76 placebo, 77 vitamins). Remission of symptoms was achieved by 78.1 and $79.4 \%$ of participants treated with placebo and vitamins by week $12(P=0.840)$, by 76.5 and $85.3 \%$ at week 26 and 75.8 and $85.5 \%$ at week 52 (effect of intervention over 52 weeks: odds ratio $(\mathrm{OR})=2.49,95 \% \mathrm{Cl} 1.12-5.51)$. Group differences in MADRS scores over time were not significant $(P=0.739)$. The risk of subsequent relapse among those who had achieved remission of symptoms at week 12 was lower in the vitamins than placebo group $(\mathrm{OR}=0.33,95 \% \mathrm{Cl} 0.12-0.94)$.

\section{Conclusions}

B vitamins did not increase the 12-week efficacy of antidepressant treatment, but enhanced and sustained antidepressant response over 1 year. Replication of these findings would mandate that treatment guidelines adopt the adjunctive use of B vitamins as a safe and inexpensive strategy to manage major depression in middle-aged and older adults.

\section{Declaration of interest}

None.
Antidepressant medications are at the forefront of the management of depressive disorders in adults. ${ }^{1}$ Their use reduces the severity of symptoms and promotes the remission of depressive episodes, ${ }^{2-4}$ but as many as $50 \%$ of patients fail to respond satisfactorily to first-line antidepressant treatment. ${ }^{5}$ Attempts to augment response to antidepressants with other agents have produced inconsistent results, and findings have been difficult to generalise because of the characteristics of study samples (predominantly participants with treatment-resistant illness) and diversity of the approaches tested. ${ }^{6-8}$ This lack of success in enhancing the efficacy of antidepressant treatment is, in part, because of our fragmented understanding of the physiological pathways that lead to the development and maintenance of depressive symptoms. Nonetheless, advances have been made. A handful of clinical investigations in the 1960s reported that mental disorders, including depression, were associated with folate deficiency, ${ }^{9}$ a finding that was later confirmed by Reynolds and colleagues in a convenience sample of 101 British adults with depression. ${ }^{10}$ Subsequently, it became apparent that a large proportion of people with megaloblastic anaemia showed evidence of clinically significant depressive symptoms, either in association with deficiency of folate (vitamin $\mathrm{B}_{9}$ ) or vitamin $\mathrm{B}_{12},{ }^{11}$ leading to suggestions that these $\mathrm{B}$ vitamins could potentially lie on the causal pathway that leads to depression. ${ }^{12}$ Folate is a co-substrate of various cell reactions involved in methylation and synthesis of nucleic acid and neurotransmitters, such as serotonin, dopamine and noradrenaline. ${ }^{13}$ The intracellular concentrations of folate and vitamin $B_{12}$ can be inferred, indirectly, through the total plasma concentration of homocysteine (tHcy), which can be converted to methionine through an enzymatic reaction that uses 5-methyletetrahydrofolate as the methyl donor group. ${ }^{13}$ Consequently, the plasma concentration of homocysteine falls as the intracellular concentration of various folates and vitamin $B_{12}$ rises. Numerous observational studies have since confirmed that depression, particularly in later life, is associated with relatively low concentrations of folate and vitamin $B_{12}$, as well as with high tHcy, ${ }^{14-17}$ although vitamin supplementation has negligible effects on the mood of adults and older adults free of clinically significant depressive symptoms. ${ }^{18-20}$

A meta-analysis of genetic association studies showed that a common polymorphism of the methylenetetrahydrofolate reductase (MTHFR) enzyme that increases the basal concentration of tHcy also increases the risk of depression, ${ }^{21}$ suggesting that high tHcy lies on the causal pathway that leads to depression in later life. The findings of four small double-blind clinical trials published in the mid 1980s and 1990s were generally consistent with a causal relationship between high tHcy and depression: they reported that folate supplementation improves response to antidepressant treatment, albeit inconsistently. ${ }^{22-25}$ More recently, a secondary analysis of a randomised, placebo-controlled, double-blind trial of folate, vitamin $B_{12}$ and vitamin $B_{6}$ to prevent cardiovascular events among stroke survivors showed that participants assigned 
vitamins had lower risk of experiencing a depressive episode over 7 years than those treated with placebo. ${ }^{26}$ Data from a randomised, double-blind, placebo-controlled augmentation trial of 75 adults with major depression resistant to treatment with a selective serotonin reuptake inhibitor (SSRI) showed that $15 \mathrm{mg} /$ day of l-methylfolate decreased the severity of symptoms and increased remission over 60 days. ${ }^{27}$ These results suggest that the use of folate and vitamin $B_{12}$ may increase the efficacy of standard antidepressant treatment in an unselected sample of adults with major depression and, potentially, prevent relapse over time. ${ }^{28}$ However, supportive trial evidence is not currently available. B-VITAGE was a randomised, double-blind, placebocontrolled trial designed to assess the short- and long-term efficacy of antidepressant treatment associated with B vitamins or placebo for 1 year (registered with the Australian and New Zealand Clinical Trials Registry (ANZCTR): 12609000256279). We hypothesised that a greater proportion of adults aged 50 years or over with major depression assigned treatment with citalopram and vitamins $\mathrm{B}_{6}, \mathrm{~B}_{12}$ and folate would experience remission of symptoms after 12 and 52 weeks than would controls treated with citalopram and placebo. We also hypothesised that relapse after remission of symptoms by week 12 would be more frequent among participants treated with placebo than with vitamins.

\section{Method}

\section{Trial design}

B-VITAGE was a 1-year parallel, randomised, double-blind, controlled trial of citalopram and adjunctive treatment with vitamins $\mathrm{B}_{6}, \mathrm{~B}_{12}$ and folate or placebo. The allocation ratio was 1:1. Three weeks after the trial commenced, the lower age limit of participants was decreased from 60 to 50 years to facilitate recruitment and increase the generalisability of findings. The Human Ethics Committee of the Royal Perth Hospital approved the study protocol ${ }^{29}$ and all participants provided written informed consent.

\section{Participants}

Eligibility criteria included: (a) age 50 years or over, (b) major depressive episode in the context of a major depressive disorder (single episode or recurrent) according to DSM-IV-TR criteria; ${ }^{30}$ (c) a Montgomery- ̊̊sberg Depression Rating Scale (MADRS) score $\geqslant 20 ;^{31}$ (d) fluency in written and spoken English; (e) Alcohol Use Disorders Identification Test (AUDIT) $\leqslant 15 ;^{32}$ (f) Mini-Mental State Examination (MMSE) score $\geqslant 24 ;{ }^{33}(\mathrm{~g})$ negative clinical history for stroke or neurodegenerative diseases (such as Parkinson's disease); (h) negative clinical history of allergic reactions to citalopram or escitalopram; (i) negative clinical history of life-threatening illness likely to compromise 1-year survival (such as metastatic cancer); ( $\mathrm{j}$ ) no evidence of prominent psychotic symptoms or suicidal intent; (k) negative clinical history for schizophrenia, schizoaffective disorder or bipolar disorder; and (l) not undergoing electroconvulsive therapy or using antidepressants at the baseline assessment.

Participants were community-dwelling adults living in the Perth metropolitan region. We used the electoral roll (voting is compulsory in Australia) to send information about the study and a brief screening questionnaire that included the Patient Health Questionnaire (PHQ-9). ${ }^{34}$ Thirty-five participants were referred by local general practitioners (GPs). Consenting adults interested in the study posted the screening questionnaire back to the research office and those with PHQ-9 $\geqslant 10$ and AUDIT $\leqslant 15$ were invited for a face-to-face assessment at the Royal Perth Hospital that included assessment with the Mini-International
Neuropsychiatric Interview (MINI) structured clinical interview, which produces diagnostic groupings consistent with DSM-IV-TR criteria. $^{35}$

\section{Interventions}

Eligible participants were randomly assigned to treatment with citalopram plus $0.5 \mathrm{mg}$ of vitamin $\mathrm{B}_{12}, 2 \mathrm{mg}$ of folic acid and $25 \mathrm{mg}$ of vitamin $\mathrm{B}_{6}$, or citalopram plus placebo. The prescribed dosages of vitamins are effective in reducing tHcy by about $20 \%{ }^{36}$ Citalopram was introduced at a daily dosage of $10 \mathrm{mg}$ and, 2 weeks later, it was increased to $20 \mathrm{mg}$. Flexible adjustment of the daily dosage of citalopram occurred at 4 and 8 weeks up to a maximum of $40 \mathrm{mg}$. These adjustments were guided by the persistence of depressive symptoms and side-effects of treatment, as determined by a certified psychiatrist. After 12 weeks, the management of antidepressant treatment was devolved to the GP of participants, who could choose to maintain the citalopram or change antidepressants. We advised GPs to maintain treatment with citalopram for an additional 9 months for patients whose depressive episode had remitted after 3 months. Participants were actively encouraged to maintain treatment with vitamins or placebo for 52 weeks. The Royal Perth Hospital Pharmacy dispensed the vitamins/placebo at baseline, 4, 8, 12 and 26 weeks. Vitamins and placebo were administered in the form of one daily capsule consumed after breakfast.

Participants of this trial were explicitly instructed not to use vitamin supplements for the duration of the study.

\section{Outcomes}

The primary outcome of interest of this study was remission of DSM-IV-TR major depressive episode after 12, 26 and 52 weeks of treatment, as assessed by the MINI. ${ }^{35}$ A reduction of $50 \%$ or more in the MADRS scores over the same period was another outcome of interest. ${ }^{31}$ Secondary outcomes included reduction of MADRS scores over time (4, 8, 12, 26 and 52 weeks), relapse of major depressive symptoms following remission by 12 weeks (26 and 52 weeks) and change from citalopram to another antidepressant.

We collected data on age (in years), gender, place of birth, marital status, past self-reported clinical history of cardiovascular diseases (such as coronary heart disease), chronic respiratory diseases (such as asthma or emphysema), diabetes, hearing impairment and history of past depression. More specifically, we asked: 'Have you ever been told by a doctor that you had depression?' Possible answers to this question were 'yes' or 'no'. Participants maintained a medication diary for the duration of the study, where they recorded all medications consumed each day of the year (including changes of antidepressants). In addition, bottles containing the study tablets (citalopram for 12 weeks and vitamins/placebo for 52 weeks) were returned to the pharmacy at each assessment $(4,8,12,26$ and 52 weeks) and the number of pills dispensed, consumed and returned were recorded. Individuals who had consumed at least $75 \%$ of the study tablets prescribed were considered to have adhered to treatment.

During the face-to-face assessments (weeks 4, 8, 12, 26 and 52) participants were asked about adverse effects experienced since their last visit, and rated their presence as 'not at all or a little' or 'quite a bit or a lot' for: tremor of the hands, muscle stiffness, involuntary muscle contractions, muscle cramps, pins and needles in the body, difficulty concentrating, agitation or restlessness, irritability, dizzy of faint, headache, other pain, arthritis or pain in the joints, nausea, diarrhoea, constipation, vomiting, anorexia, weight loss, weight gain, skin rash, nightmares, excessive 
somnolence, poor sleep, palpitations, dry mouth, other such as delayed ejaculation or anorgasmia. Complaints that were present at baseline (i.e. before the start of treatment) and that persisted at the same level of intensity during follow-up were not attributed to treatment.

Fasting blood samples were collected at $08.00 \mathrm{~h}$ on the day of the baseline assessment, and again after 12, 26 and 52 weeks. We used chemiluminescent microparticle immunoassay (CMIA) technology to measure tHcy on an Architect i2000SR Analyser (Abbott Ireland Diagnostics Division, Lisnamuck, Longford Co., Longford, Ireland). The coefficient of variation of the assay ranges from 2.3 to $2.8 \%$. Red cell folate and serum $B_{12}$ were assayed with the Immulite $200 \mathrm{XPi}$ (Siemens Healthcare Diagnostic Ltd. Llanberis, Gwynedd) and the Architect i2000SR Analyser. Coefficients of variations were 3.5 and $4.5-8.6 \%$, respectively.

\section{Sample size}

We based our sample size calculations on published data from a trial that used folic acid together with fluoxetine for treatment of adults aged 18 years and older with depression. ${ }^{25}$ They reported that $64.7 \%$ of participants treated with fluoxetine and folic acid were free of symptoms after 10 weeks compared with $48.3 \%$ of those who had been treated with fluoxetine and placebo. We calculated that a study with 310 participants (155 in each treatment arm) would have $80 \%$ power to declare such a difference between the groups as significant ( $\alpha$ : $5 \%$, two-tailed). We estimated that $15 \%$ of participants would have been lost by the end of week 12 , and another $10 \%$ by week 52 , resulting in a target sample of 388 people (194 per group). ${ }^{29}$ We screened 2150 people, interviewed 478 and randomised 153 (Fig. 1). The addition of two panels of data at 26 and 52 weeks was expected

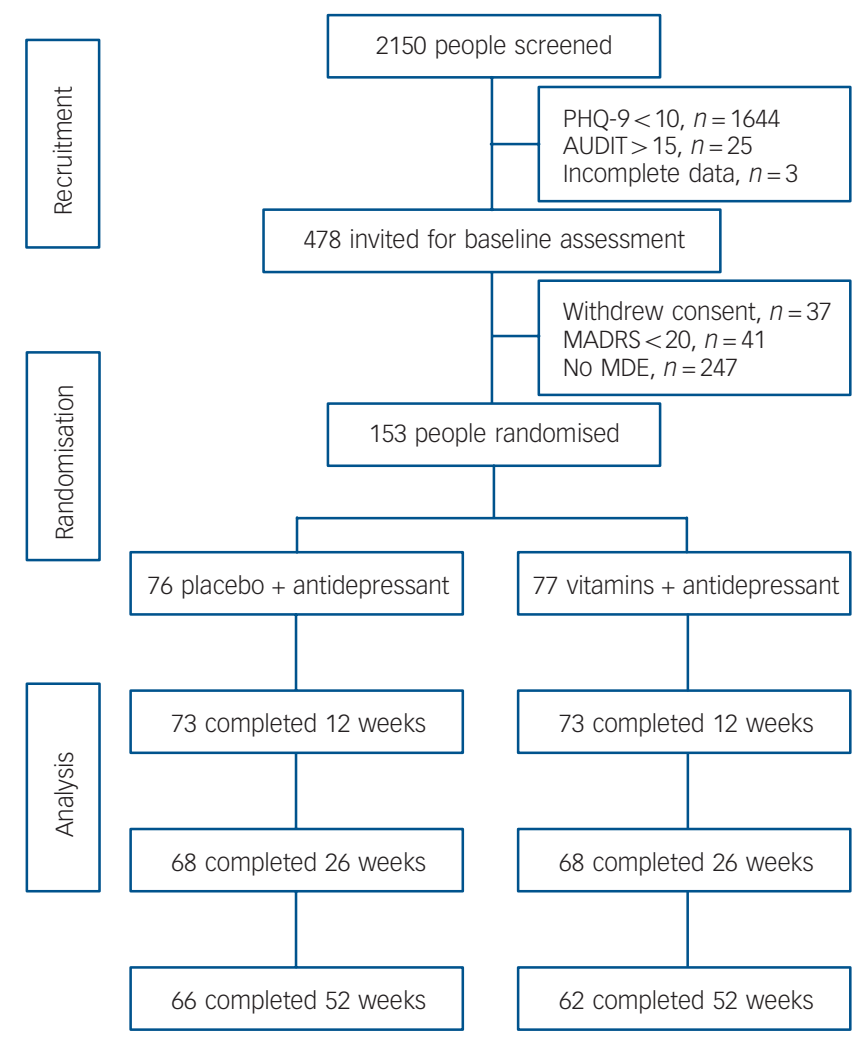

Fig. 1 Flow of trial participants from the time of screening to analysis.

PHQ-9, Patient Health Questionnaire; AUDIT, Alcohol Use Disorders Identification Test; MADRS, Montgomery-Åsberg Depression Rating Scale; MDE, Major Depressive Episode according to DSM-IV criteria. to circumvent the possible loss of power caused by the lower than planned number of participants recruited. ${ }^{37}$

\section{Randomisation and masking}

The pharmacy of the Royal Perth Hospital carried out the independent randomisation of participants according to a list of random numbers generated by computer in random permuted blocks of 6 to 16 (1:1 allocation). Vitamins and placebo were dispensed in the form of daily capsules that had the same size, shape, colour, texture, smell and taste. Blackmores Australia manufactured all capsules. Investigators and participants remained masked to treatment assignment until all participants had completed all assessments. In addition, both investigators and study participants remained masked to the results of biochemical analyses until the final collection of end-points in September 2013.

\section{Statistical analyses}

The data were managed and analysed using the statistical software package Stata version 13.0 for Mac. We used descriptive statistics to describe the sociodemographic and clinical characteristics of participants, and Pearson's chi-squared tests, Mann-Whitney ranked sum tests and Student's $t$-tests to compare their distribution among those assigned to placebo and vitamins. Outcomes were analysed as panel data and made use of all data available at each time point. (That is, all data, including available information for participants lost to follow-up, were entered in these models and contributed to its final intention-to-treat results. In this case, no assumptions were made about missing data that could potentially bias the study findings). We used xtlogit to analyse binary outcomes such as remission of depressive episode (yes/no) (effect estimate expressed as odds ratio (OR) and respective 95\% confidence intervals) and multilevel mixed-effects linear regression (xtmixed) to analyse changes of MADRS scores over time (effect estimate expressed as mean change of score). These analyses were adjusted for gender and baseline tHcy imbalances. Finally, we used contingency tables to calculate the number needed to treat (NNT) for one person to benefit from vitamin treatment, taking into account the number of participants lost to follow-up. The NNT is the reverse of the absolute risk reduction.

\section{Results}

Figure 1 shows the flow of participants from screening to analysis. The first participant entered the study on the 31 March 2009 and the last exited the study on the 11 September 2013. The age of the 153 participants ranged from 50 to 85 years and 86 of them $(56.2 \%)$ were women. Table 1 shows the characteristics of participants randomly allocated to treatment with placebo and vitamins at their baseline assessment. Treatment groups were well balanced for most measured factors, except for a non-significant excess of women in the placebo group and significantly higher tHcy among those assigned vitamins. None of the participants showed evidence of low concentration of red cell folate $(<260 \mathrm{nmol} / \mathrm{L})$ or of serum vitamin $\mathrm{B}_{12}(<140 \mathrm{pmol} / \mathrm{L})$.

Intention-to-treat analysis using xtlogit showed that more people treated with vitamins than placebo experienced remission over 52 weeks $(\mathrm{OR}=2.49,95 \%$ CI 1.12-5.51, after adjustment for gender and baseline tHcy, Table 2). The interaction between time and intervention grouping was not statistically significant. Treatment with vitamins was associated with $6.5 \%$ absolute risk reduction of major depression by 52 weeks (taking into account loss to follow-up), indicating that 16 people would require treatment for one to benefit. These calculations assumed that loss 
Table 1 Characteristics of participants with major depression at study entry according to their random assignment to treatment with citalopram + placebo or citalopram + vitamins.

\begin{tabular}{|c|c|c|c|c|c|c|}
\hline & $\begin{array}{l}\text { Placebo group } \\
\qquad(n=76)\end{array}$ & $\begin{array}{l}\text { Vitamins group } \\
\qquad(n=77)\end{array}$ & $\chi^{2}$ (d.f.) & $z^{a}$ & $t$-test (d.f.) & $P$ \\
\hline Age, years: mean (s.d.) & $61.7(8.2)$ & $63.4(7.4)$ & & & $-1.37(151)$ & 0.173 \\
\hline Age, years, $n(\%)$ & & & 3.85 (3) & & & 0.278 \\
\hline $50-59$ & $37(48.7)$ & $27(35.1)$ & & & & \\
\hline $60-69$ & $26(34.2)$ & $37(48.0)$ & & & & \\
\hline $70-79$ & $11(14.5)$ & $12(15.6)$ & & & & \\
\hline$\geqslant 80$ & $2(2.6)$ & $1(1.3)$ & & & & \\
\hline Female gender, $n(\%)$ & $48(63.2)$ & $38(49.3)$ & $2.96(1)$ & & & 0.085 \\
\hline Migrant, $n(\%)$ & $9(11.8)$ & $5(6.5)$ & $1.32(1)$ & & & 0.251 \\
\hline Marital status, $n(\%)$ & & & $0.63(1)$ & & & 0.890 \\
\hline Single & $5(6.6)$ & $6(7.8)$ & & & & \\
\hline Married & $41(53.9)$ & $44(57.1)$ & & & & \\
\hline Separated or divorced & $25(32.9)$ & $21(27.3)$ & & & & \\
\hline Widowed & $5(6.6)$ & $6(7.8)$ & & & & \\
\hline Body mass index group, $n(\%)^{b}$ & & & $0.57(2)$ & & & 0.754 \\
\hline Normal & $19(25.3)$ & $16(20.8)$ & & & & \\
\hline Overweight & $33(44.0)$ & $34(44.2)$ & & & & \\
\hline Obese & $23(30.7)$ & $27(35.1)$ & & & & \\
\hline \multicolumn{7}{|l|}{ Comorbid diagnoses, $n(\%)$} \\
\hline Cardiovascular diseases & $11(14.5)$ & $9(11.7)$ & $0.26(1)$ & & & 0.609 \\
\hline Chronic respiratory diseases & $19(25.0)$ & $15(19.5)$ & $0.67(1)$ & & & 0.412 \\
\hline Diabetes & $8(10.5)$ & $10(13.0)$ & $0.22(1)$ & & & 0.637 \\
\hline Hearing impairment & $16(21.0)$ & $16(20.8)$ & $0.00(1)$ & & & 0.967 \\
\hline Past diagnosis of depression, $n(\%)$ & $58(76.3)$ & $59(77.6)$ & $0.04(1)$ & & & 0.847 \\
\hline MMSE, median (IQR) & $29(28-30)$ & $29(28-30)$ & & 0.345 & & 0.730 \\
\hline MADRS, median (IQR) & $27(22-32)$ & $26(24-31)$ & & 0.17 & & 0.865 \\
\hline Homocysteine, $\mu \mathrm{mol} / \mathrm{L}$ : median (IQR) & $10.3(8.9-11.6)$ & $11.2(9.3-12.9)$ & & 2.07 & & 0.039 \\
\hline Red cell folate, nmol/L: median (IQR) & $1268(1067-1721)$ & $1352(1002-1740)$ & & 0.18 & & 0.851 \\
\hline $\mathrm{B}_{12}, \mathrm{pmol} / \mathrm{L}:$ median (IQR) & $370(300-490)$ & $351(266-430)$ & & 1.40 & & 0.163 \\
\hline
\end{tabular}

to follow-up had occurred at random. If we assume that all participants lost to follow-up had negative outcomes (worst possible scenario), then the number needed to treat would have been 33 . We also assessed the effect of treatment without adjusting the analyses for the gender and tHcy imbalance. The non-adjusted analyses showed a diminished effect of the intervention $(\mathrm{OR}=1.76$, 95\% CI 0.81-3.82), mostly because women had significantly lower tHcy at baseline than men (mean difference $1.4,95 \%$ CI $1.0-1.8, P<0.001)$. When we limited the unadjusted analyses to those in the highest 50 percentile of tHcy, the effect of the intervention was statistically significant $(\mathrm{OR}=2.71,95 \% \mathrm{CI}$ 1.03-7.10) and consistent with the main results of the trial.

After 12 weeks of treatment, 78.1 and $79.4 \%$ of participants treated with citalopram plus placebo and citalopram plus vitamins no longer fulfilled criteria for a major depressive episode $(P=0.840$, Table 2$)$. The odds of remission in the vitamin group relative to the placebo group was 1.55 (95\% CI 0.64-3.72, after adjustment for gender and baseline tHcy). By week 26 the adjusted odds of remission associated with vitamin treatment was 2.32 (95\% CI $0.91-5.97$ ), and by the end of 1 year 2.54 (95\% CI 0.94-6.80). There was no evidence that adjunctive treatment with vitamins was associated with faster or more pronounced reduction of MADRS scores over 12 (Table 2) and 52 weeks (Fig. 2). However, among those who were no longer depressed by week 12 , relapse of symptoms at 26 and 52 weeks was less frequent among participants assigned vitamins than placebo ( $\mathrm{OR}=0.33,95 \%$ CI $0.12-0.94)$.

Table 3 summarises data on adherence to treatment with citalopram and vitamins/placebo, as well changes of antidepressants and adverse experiences of participants assigned treatment with placebo and vitamins. There were no differences between the study groups in any of these measures. Moreover, there were no breaches of protocol or unmasking during the study. Finally, treatment with vitamins was associated with a significant reduction in tHcy $(-1.1 \mu \mathrm{mol} / \mathrm{L}, 95 \% \mathrm{CI}-1.4$ to $-0.7 \mu \mathrm{mol} / \mathrm{L}$; adjusted for gender and baseline tHcy), and increased red cell folate $(608.4 \mathrm{nmol} / \mathrm{L}, 95 \%$ CI 487.8 to $729.1 \mathrm{nmol} / \mathrm{L}$; adjusted for gender and baseline red cell folate) and serum $B_{12}$ (196.0 pmol/L, 95\% CI 147.2 to $244.9 \mathrm{pmol} / \mathrm{L}$; adjusted for gender and baseline serum $\mathrm{B}_{12}$ ), indicating that treatment had the expected effect on these measures (Table 4).

We also completed post hoc analyses to ascertain whether the benefits of treatment varied according to basal tHcy. The medium basal tHcy for the sample was $10.4 \mu \mathrm{mol} / \mathrm{L}$ (IQR 9.1-12.3 $\mu \mathrm{mol} / \mathrm{L}$ ). Restriction of the analyses to the subgroup of 76 participants (32 placebo, 44 vitamins) with tHcy $>10.4 \mu \mathrm{mol} / \mathrm{L}$ confirmed that the use of vitamins was associated with greater odds of remission of symptoms over 52 weeks compared with placebo $(\mathrm{OR}=3.47$, 95\% CI 1.22-9.84). Conversely, those with tHcy $\leqslant 10.4 \mu \mathrm{mol} / \mathrm{L}$ at baseline showed no evidence of benefiting from treatment with vitamins ( $\mathrm{OR}=1.09,95 \%$ CI $0.32-3.75)$.

\section{Discussion}

\section{Main findings}

This placebo-controlled randomised trial showed that the adjunctive use of folic acid, vitamin $B_{6}$ and vitamin $B_{12}$ is safe and more effective than placebo at enhancing response to 
Table 2 Clinical outcomes over time of participants with major depression treated with placebo or vitamins ${ }^{\text {a }}$

\begin{tabular}{|c|c|c|c|c|}
\hline & \multicolumn{2}{|c|}{$n / N(\%)$} & \multicolumn{2}{|c|}{ OR $(95 \% \mathrm{Cl})$} \\
\hline & Placebo group & Vitamins group & Effect of time, ${ }^{b}$ within group & Effect of vitamins, ${ }^{b}$ between group \\
\hline \multicolumn{5}{|c|}{ Major depressive episode in remission ${ }^{c}$} \\
\hline Week 12 & $57 / 73(78.1)$ & $58 / 73(79.4)$ & 1 (Reference) & $2.49(1.12-5.51)$ \\
\hline Week 26 & $52 / 68(76.5)$ & $58 / 68(85.3)$ & $1.16(0.60-2.29)$ & \\
\hline Week 52 & $50 / 66(75.8)$ & $53 / 62(85.5)$ & $1.14(0.57-2.26)$ & \\
\hline \multicolumn{5}{|c|}{$\geqslant 50 \%$ reduction in MADRS score } \\
\hline Week 4 & 38/74 (51.3) & $34 / 73(46.6)$ & 1 (Reference) & $0.59(0.28-1.25)$ \\
\hline Week 8 & $56 / 73(76.7)$ & $46 / 72(63.9)$ & $4.04(2.16-7.57)$ & \\
\hline Week 12 & $56 / 73(76.7)$ & $47 / 73(64.4)$ & $4.07(2.18-7.61)$ & \\
\hline \multicolumn{5}{|c|}{ Relapse after week $12^{d}$} \\
\hline Week 26 & 10/57 (17.5) & $5 / 58(8.6)$ & 1 (Reference) & $0.33(0.12-0.94)^{\mathrm{e}}$ \\
\hline Week 52 & 10/57 (17.5) & $5 / 57(8.8)$ & $1.02(0.44-2.37)$ & \\
\hline \multicolumn{5}{|c|}{$\begin{array}{l}\text { MADRS, Montgomery-Åsberg Depression Rating Scale score. } \\
\text { a. n/N: number of participants in the cell/number of participants available in the group. } \\
\text { b. Analyses adjusted for gender and baseline total plasma homocysteine. } \\
\text { c. Major depressive episode according to DSM-IV-TR criteria. Number needed to treat (NNT) for } 1 \text { person to benefit by } 52 \text { weeks is } 16 \text {. If all individuals lost to follow-up were still } \\
\text { clinically depressed, then the NNT is } 33 \text {. } \\
\text { d. A total of } 57 \text { and } 58 \text { participants treated with placebo and vitamins, respectively, were in remission by week } 12 \text { - this subgroup was followed up to investigate relapse of } \\
\text { symptoms at weeks } 26 \text { and } 52 \text {. } \\
\text { e. Baseline total plasma homocysteine not included in these analyses, as relapse could only occur at or after week } 26 \text {. }\end{array}$} \\
\hline
\end{tabular}

antidepressant treatment over 52 weeks, but not over the initial 12 weeks. The effect of treatment with vitamins on symptom severity was not significant compared with placebo. In addition, relapse of major depression for participants who had experienced remission of symptoms by 12 weeks was less frequent among those treated with vitamins than with placebo. The beneficial effects of vitamins on mood was apparent among those in the highest 50th percentile of tHcy, but not among those in the bottom half of tHcy values.

\section{Strengths and limitations}

This single-site trial had a relatively small sample size and had to stop recruitment before the planned number of participants had been reached. The possible loss of power associated with decreased sample size was mitigated, in part, by the availability of repeated measures, ${ }^{37}$ which allowed us to analyse all available data and minimise the introduction of bias (intention-to-treat analyses). The randomisation of participants was centralised and independent

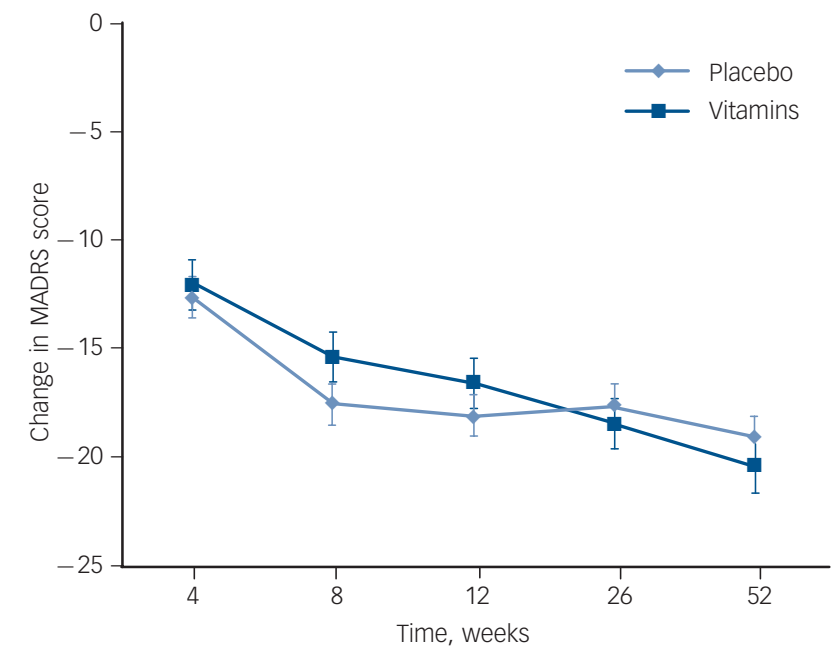

Fig. 2 Mean change in Montgomery-Åsberg Depression Rating Scale (MADRS) scores from baseline over a period of 52 weeks for people treated with placebo and vitamins.

The whiskers represent the standard error of the mean change at each time point. All estimates were adjusted for baseline MADRS scores and gender. Treatment with vitamins was associated with a non-significant decline of 0.4 points over time compared with placebo ( $95 \% \mathrm{Cl}-2.6$ to $1.8, z=-0.74, P=0.739$; analysis adjusted for gender and baseline total plasma homocysteine). of the investigators, and masking was maintained throughout the trial. The sample consisted of volunteers who consented to screening and who were subsequently diagnosed with a major depressive episode. The use of the electoral roll to approach participants living in the community might have yielded a sample that differs from samples recruited from specialised mental health services, and this might explain the relatively high proportion of participants who responded well to treatment. ${ }^{5}$ In addition, the outcome measures that we used in this trial to establish the presence of major depression and to monitor changes in the severity of symptoms have well-established validity. ${ }^{31,35}$ This, together with the background characteristics of our sample, gives us confidence that our results are most likely applicable and generalisable to middle-aged and older adults with major depression living in the community.

Contamination caused by the use of vitamins not prescribed by the study could represent another potential source of error in our trial, although participants were explicitly instructed not to use any other B vitamins. The consequence of such contamination would have been loss of power to declare as statistically significant differences between the groups (because some placebo-treated patients would have benefited from treatment with B vitamins). In that case, our findings could be considered conservative. However, we did have objective measures of adherence with the treatment protocol that also included blood tests. Total plasma homocysteine remained unchanged in the placebo group throughout the trial, but declined (as expected) among actively treated participants. Similarly, changes in the concentration of red cell folate and of vitamin $B_{12}$ increased markedly among participants randomised to treatment with vitamins but not with placebo (Table 4). For these reasons, we are inclined to conclude that contamination is unlikely to have significantly affected the results of our trial.

Given the apparent beneficial results of the intervention, it might seem surprising that we did not find a significant difference in MADRS scores over time between the groups. We would suggest that this might have been as a result of the marked beneficial effect of the interventions on scores, which left little room to explore differences between the groups over time. We have also assumed that loss to follow-up in this trial occurred at random. Although our results are consistent with this interpretation, it is conceivable that those who did not return for assessment could have all done poorly. If that were the case, 


\begin{tabular}{|c|c|c|c|c|}
\hline & \multicolumn{2}{|c|}{$n / N(\%)$} & \multicolumn{2}{|c|}{ OR $(95 \% \mathrm{Cl})$} \\
\hline & Placebo group & Vitamins groups & Effect of time, within group & Effect of vitamins, between group \\
\hline \multicolumn{5}{|c|}{ Adherence with citalopram } \\
\hline Week 4 & 68/74 (91.9) & 68/73 (93.1) & 1 (Reference) & $0.77(0.09-6.44)$ \\
\hline Week 8 & $58 / 73(79.4)$ & $65 / 74(87.8)$ & $0.11(0.02-0.52)$ & \\
\hline Week 12 & $64 / 73(87.7)$ & $57 / 74(77.0)$ & $0.36(0.08-1.71)$ & \\
\hline \multicolumn{5}{|c|}{ Adherence with vitamins } \\
\hline Week 4 & 68/74 (91.9) & 68/73 (93.1) & 1 (Reference) & $0.86(0.33-2.25)$ \\
\hline Week 8 & 60/73 (82.2) & 65/72 (90.3) & $0.36(0.14-0.93)$ & \\
\hline Week 12 & $69 / 73(94.5)$ & $57 / 73(78.1)$ & $0.36(0.14-0.93)$ & \\
\hline Week 26 & $56 / 68(82.3)$ & $57 / 68(83.8)$ & $0.22(0.08-0.57)$ & \\
\hline Week 52 & $55 / 66$ (83.3) & $48 / 62(77.4)$ & $0.16(0.06-0.42)$ & \\
\hline \multicolumn{5}{|c|}{ Change of antidepressant } \\
\hline Week 4 & 1/74 (1.3) & 0/73 & & $-{ }^{\mathrm{b}}$ \\
\hline Week 8 & $3 / 73(4.1)$ & 0/72 & & \\
\hline Week 12 & $3 / 73(4.1)$ & 0/73 & & \\
\hline Week 26 & 9/68 (13.2) & $7 / 68(10.3)$ & & \\
\hline Week 52 & $7 / 66(10.6)$ & $10 / 62(16.1)$ & & \\
\hline \multicolumn{5}{|c|}{ Adverse effects at any time ${ }^{c}$} \\
\hline Tremor & 6/72 (8.3) & $7 / 65$ (10.8) & - & $1.33(0.42-4.18)$ \\
\hline Agitation, anxiety & 10/35 (28.6) & $9 / 30(30.0)$ & - & $1.07(0.37-3.13)$ \\
\hline Headache & $16 / 63(25.4)$ & $10 / 50(20.0)$ & - & $0.74(0.30-1.80)$ \\
\hline Nausea & 7/71 (9.9) & $4 / 66(6.1)$ & - & $0.59(0.16-2.12)$ \\
\hline Diarrhoea & $4 / 70(5.7)$ & $7 / 64(10.9)$ & - & $2.03(0.56-7.28)$ \\
\hline Constipation & $8 / 63(12.7)$ & $8 / 61(13.1)$ & - & $1.04(0.36-2.97)$ \\
\hline Nightmares & $7 / 61(11.5)$ & 11/59 (18.6) & - & $1.77(0.63-4.92)$ \\
\hline Dry mouth & $14 / 63(22.2)$ & 19/54 (35.2) & - & $1.90(0.84-4.29)$ \\
\hline Sexual & $8 / 72(11.1)$ & $12 / 74(16.2)$ & - & $1.55(0.59-4.05)$ \\
\hline Lost during follow-up & 10/76 (13.2) & 15/77 (19.5) & - & $1.60(0.62-4.28)$ \\
\hline
\end{tabular}

Table 4 Changes in total plasma homocysteine, red cell folate and serum $\mathrm{B}_{12}$ relative to baseline during the course of the trial

\begin{tabular}{|c|c|c|c|c|}
\hline & \multicolumn{2}{|c|}{ Mean $(\text { s.e. })^{a}$} & \multicolumn{2}{|c|}{ Mean difference $(95 \% \mathrm{Cl})$} \\
\hline & Placebo & Vitamins & Effect of time, ${ }^{b}$ within group & Effect of vitamins, between group \\
\hline \multicolumn{5}{|c|}{ Plasma homocysteine, $\mu \mathrm{mol} / \mathrm{L}$} \\
\hline Week 12 & $0.3(0.2)$ & $-1.4(0.2)$ & $-0.5(-0.9$ to -0.2$)$ & $-1.1(-1.4$ to -0.7$)$ \\
\hline Week 26 & $0.3(0.2)$ & $-1.6(0.3)$ & $-0.6(-1.0$ to -0.3$)$ & \\
\hline Week 52 & $-0.2(0.2)$ & $-2.1(0.3)$ & $-1.1(-1.4$ to -0.7$)$ & \\
\hline \multicolumn{5}{|c|}{ Red cell folate, $\mathrm{nmol} / \mathrm{L}$} \\
\hline Week 12 & $10.9(80.5)$ & 829.7 (92.3) & 412.1 (283.1 to 541.1 ) & 608.4 (487.8 to 729.1$)$ \\
\hline Week 26 & $117.2(101.5)$ & $885.2(94.8)$ & 497.2 (364.7 to 629.8) & \\
\hline Week 52 & $-64.2(89.2)$ & $864.7(112.6)$ & $393.8(259.4$ to 528.1$)$ & \\
\hline \multicolumn{5}{|c|}{ Vitamin $\mathrm{B}_{12}, \mathrm{pmol} / \mathrm{L}$} \\
\hline Week 12 & $-13.8(9.0)$ & $225.5(20.2)$ & 106.4 (53.0 to 159.8 ) & 196.0 (147.2 to 244.9$)$ \\
\hline Week 26 & $30.4(44.6)$ & $299.7(35.8)$ & 165.4 (110.5 to 220.2$)$ & \\
\hline Week 52 & $23.1(40.4)$ & $339.0(50.0)$ & 177.6 (122.0 to 233.2 ) & \\
\hline
\end{tabular}

the absolute risk reduction associated with vitamins compared with placebo could be as low as $3 \%$, and the $\mathrm{NNT}=33$. In this worst possible scenario, the use of vitamins would still enhance response to antidepressant treatment, but benefits would be small.

We also acknowledge that we cannot be certain about the effects of ongoing treatment with these vitamins beyond 52 weeks. Existing data suggest that extended treatment with these dosages of $B$ vitamins is generally safe ${ }^{13,38}$ and that long-term consumption might contribute to preventing depressive episodes among those at risk. ${ }^{26}$ However, evidence from prolonged randomised clinical trials targeting people with or at risk of depression is not available. It is also important to note that none of our participants was $B_{12}$ or folate deficient. Australia is a wealthy country where fortification of flour with folic acid is mandated and, as a result, folate deficiency is now rare. ${ }^{39}$ This suggests that the potential antidepressant effects of these vitamins could be more pronounced in countries where deficiency of vitamins $B_{12}$ and folate is common. A similar rationale would suggest that such an intervention might be particularly relevant for adults with depression aged 75 years or older, which is the age group with the highest $\mathrm{tHcy.}{ }^{36}$

\section{Implications}

Existing observational data indicate that high tHcy and low folate increase the risk of depression and are associated with more frequent symptom relapse and treatment resistance. ${ }^{21,28,40} \mathrm{~A}$ 
recent trial showed that folate supplementation increases response to antidepressant treatment in adults with treatment-resistant depression, ${ }^{27}$ and our results now extend these findings to a community-derived unselected sample of middle-aged and older adults with major depression. In this trial, the use of vitamins $\mathrm{B}_{6}, \mathrm{~B}_{12}$ and folate did not increase the 12-week efficacy of antidepressant treatment, but enhanced and sustained antidepressant response over 1 year. Participants in the highest 50th percentile of plasma tHcy benefited the most from the use of these vitamins. Replication of these findings would mandate that treatment guidelines adopt the adjunctive use of $\mathrm{B}$ vitamins as a safe and inexpensive strategy to manage major depression in middle-aged and older adults.

Osvaldo P. Almeida, MD, PhD, FRANZCP, Andrew H. Ford, MBBS, PhD, FRANZCP WA Centre for Health \& Ageing, Centre for Medical Research, Perth, School of Psychiatry \& Clinical Neurosciences, University of Western Australia, Perth and Department of Psychiatry, Royal Perth Hospital, Perth; Varsha Hirani, BSC, WA Centre for Health \& Ageing, Centre for Medical Research, Perth, School of Psychiatry \& Clinical Neurosciences, University of Western Australia, Perth; Vash Singh, MBBS, FRANZCP, Department of Psychiatry, Royal Perth Hospital, Perth; Frank M. vanBockxmeer, PhD, Department of Clinical Biochemistry, PathWest Laboratory Medicine WA, Royal Perth Hospital, Perth; Kieran Mccaul, PhD, WA Centre for Health \& Ageing, Centre for Medical Research, Perth; Leon Flicker, MBBS, PhD, FRACP, School of Psychiatry \& Clinical Neurosciences, University of Western Australia Perth, School of Medicine and Pharmacology, University of Western Australia, Perth and Department of Geriatric Medicine, Royal Perth Hospital, Perth, Australia

Correspondence: Osvaldo P. Almeida, School of Psychiatry \& Clinical Neurosciences (M573), University of Western Australia, 35 Stirling Highway, Crawley, Perth, WA 6009, Australia. Email: osvaldo.almeida@uwa.edu.au

First received 19 Jan 2014, final revision 1 Jun 2014, accepted 6 Jun 2014

\section{Funding}

This project was supported by a competitive research project grant from the National Health and Medical Research Council of Australia (NHMRC, project grant 572594). The sponsors had no role in the design and conduct of the study; collection, management, analysis and interpretation of the data; or preparation, review or approval of the manuscript.

\section{Acknowledgements}

We thank study participants for their generous contribution to this study, and Dr Stephen Fenner, Ms Jennifer Tasker and Ms Natalie DiRenzo for their assistance with recruitment and data collection.

\section{References}

1 Gelenberg AJ, Freeman MP, Markowitz JC, Rosenbaum JF, Thase ME, Trived $\mathrm{MH}$, et al. Practice guideline for the treatment of patients with major depressive disorder, third edition. Am J Psychiatry 2010; 167 (suppl): 1-3, 9-11, 3-118.

2 Wilson K, Mottram P, Sivanranthan A, Nightingale A. Antidepressant versus placebo for depressed elderly. Cochrane Database Syst Rev 2001; 2 : CD000561.

3 Fournier JC, DeRubeis RJ, Hollon SD, Dimidjian S, Amsterdam JD, Shelton RC et al. Antidepressant drug effects and depression severity: a patient-level meta-analysis. JAMA 2010; 303: 47-53.

4 Cipriani A, Furukawa TA, Salanti G, Geddes JR, Higgins JP, Churchill R, et al. Comparative efficacy and acceptability of 12 new-generation antidepressants: a multiple-treatments meta-analysis. Lancet 2009; 373: 746-58.

5 Rush AJ, Trivedi MH, Wisniewski SR, Nierenberg AA, Stewart JW, Warden D et al. Acute and longer-term outcomes in depressed outpatients requiring one or several treatment steps: a STAR*D report. Am J PSychiatry 2006; 163 1905-17.

6 Fleurence R, Williamson R, Jing Y, Kim E, Tran QV, Pikalov AS, et al. A systematic review of augmentation strategies for patients with major depressive disorder. Psychopharmacol Bull 2009; 42: 57-90.

7 Dew MA, Whyte EM, Lenze EJ, Houck PR, Mulsant BH, Pollock BG, et al. Recovery from major depression in older adults receiving augmentation of antidepressant pharmacotherapy. Am J Psychiatry 2007; 164: 892-9.
8 Rush AJ, Trivedi MH, Stewart JW, Nierenberg AA, Fava M, Kurian BT, et al. Combining medications to enhance depression outcomes (CO-MED): acute and long-term outcomes of a single-blind randomized study. Am J Psychiatry 2011; 168: 689-701.

9 Carney MW. Serum folate values in 423 psychiatric patients. Br Med J 1967; 4: 512-6.

10 Reynolds EH, Preece JM, Bailey J, Coppen A. Folate deficiency in depressive illness. Br J Psychiatry 1970; 117: 287-92.

11 Shorvon SD, Carney MW, Chanarin I, Reynolds EH. The neuropsychiatry of megaloblastic anaemia. BMJ 1980; 281: 1036-8.

12 Fava M, Borus JS, Alpert JE, Nierenberg AA, Rosenbaum JF, Bottiglieri $T$. Folate, vitamin B12, and homocysteine in major depressive disorder. Am J Psychiatry 1997; 154: 426-8.

13 Smith AD, Kim YI, Refsum H. Is folic acid good for everyone? Am J Clin Nutr 2008; 87: 517-33.

14 Kim J-M, Stewart R, Kim S-W, Yang S-J, Shin I-S, Yoon J-S. Predictive value of folate, vitamin $B_{12}$ and homocysteine levels in late-life depression. Br J Psychiatry 2008; 192: 268-74.

15 Gilbody S, Lightfoot T, Sheldon T. Is low folate a risk factor for depression? A meta-analysis and exploration of heterogeneity. J Epidemiol Community Health 2007; 61: 631-7.

16 Skarupski KA, Tangney C, Li H, Ouyang B, Evans DA, Morris MC. Longitudinal association of vitamin B-6, folate, and vitamin B-12 with depressive symptoms among older adults over time. Am J Clin Nutr 2010; 92: 330-5.

17 Beydoun MA, Shroff MR, Beydoun HA, Zonderman AB. Serum folate, vitamin $\mathrm{B}-12$, and homocysteine and their association with depressive symptoms among U.S. adults. Psychosom Med 2010; 72: 862-73.

18 Andreeva VA, Galan $\mathrm{P}$, Torres $\mathrm{M}$, Julia C, Hercberg S, Kesse-Guyot $\mathrm{E}$. Supplementation with $\mathrm{B}$ vitamins or $\mathrm{n}-3$ fatty acids and depressive symptoms in cardiovascular disease survivors: ancillary findings from the Supplementation with FOLate, vitamins B-6 and B-12 and/or OMega-3 fatty acids (SU.FOL.OM3) randomized trial. Am J Clin Nutr 2012; 96: 208-14.

19 Christensen H, Aiken A, Batterham PJ, Walker J, Mackinnon AJ, Fenech M, et al. No clear potentiation of antidepressant medication effects by folic acid+vitamin B12 in a large community sample. J Affect Disord 2011; 130 $37-45$.

20 Ford AH, Flicker L, Thomas J, Norman P, Jamrozik K, Almeida OP. Vitamins B12, B6, and folic acid for onset of depressive symptoms in older men: results from a 2-year placebo-controlled randomized trial. J Clin Psychiatry 2008; 69: 1203-9.

21 Almeida OP, McCaul K, Hankey GJ, Norman P, Jamrozik K, Flicker L. Homocysteine and depression in later life. Arch Gen Psychiatry 2008; 65 1286-94.

22 Coppen A, Chaudhry S, Swade C. Folic acid enhances lithium prophylaxis. J Affect Disord 1986; 10: 9-13.

23 Godfrey PS, Toone BK, Carney MW, Flynn TG, Bottiglieri T, Laundy M, et al. Enhancement of recovery from psychiatric illness by methylfolate. Lancet 1990; 336: 392-5

24 Passeri M, Cucinotta D, Abate G, Senin U, Ventura A, Stramba Badiale M, et al. Oral 5'-methyltetrahydrofolic acid in senile organic mental disorders with depression: results of a double-blind multicenter study. Aging (Milano) 1993; 5: 63-71.

25 Coppen A, Bailey J. Enhancement of the antidepressant action of fluoxetine by folic acid: a randomised, placebo controlled trial. J Affect Disord 2000; 60 : 121-30.

26 Almeida OP, Marsh K, Alfonso H, Flicker L, Davis TM, Hankey GJ. B-vitamins reduce the long-term risk of depression after stroke: The VITATOPS-DEP trial. Ann Neurol 2010; 68: 503-10.

27 Papakostas Gl, Shelton RC, Zajecka JM, Etemad B, Rickels K, Clain A, et al. L-methylfolate as adjunctive therapy for SSRI-resistant major depression: results of two randomized, double-blind, parallel-sequential trials. Am J Psychiatry 2012; 169: 1267-74.

28 Papakostas GI, Petersen T, Mischoulon D, Green $\mathrm{CH}$, Nierenberg AA Bottiglieri T, et al. Serum folate, vitamin B12, and homocysteine in major depressive disorder, Part 2: predictors of relapse during the continuation phase of pharmacotherapy. J Clin Psychiatry 2004; 65: 1096-8.

29 Ford AH, Flicker L, McCaul K, van Bockxmeer F, Hegarty S, Hirani V, et al. The B-VITAGE trial: a randomized trial of homocysteine lowering treatment of depression in later life. Trials 2010; 11: 8.

30 American Psychiatric Association. Diagnostic and Statistical Manual of Mental Disorders (4th edn, revised) (DSM-IV-TR). APA, 2000.

31 Montgomery SA, Asberg M. A new depression scale designed to be sensitive to change. Br J Psychiatry 1979; 134: 382-9. 
32 Bohn MJ, Babor TF, Kranzler HR. The Alcohol Use Disorders Identification Test (AUDIT): validation of a screening instrument for use in medical settings. J Stud Alcohol 1995; 56: 423-32.

33 Folstein MF, Folstein SE, McHugh PR. "Mini-mental state". A practical method for grading the cognitive state of patients for the clinician. J Psychiatr Res 1975; 12: 189-98.

34 Kroenke K, Spitzer RL, Williams JB. The PHQ-9: validity of a brief depression severity measure. J Gen Intern Med 2001; 16: 606-13.

35 Sheehan DV, Lecrubier $\mathrm{Y}$, Sheehan $\mathrm{KH}$, Amorim $\mathrm{P}$, Janavs J, Weiller $\mathrm{E}$, et al. The Mini-International Neuropsychiatric Interview (M.I.N.I.): the development and validation of a structured diagnostic psychiatric interview for DSM-IV and ICD-10. J Clin Psychiatry 1998; 59 (suppl 20): 22-33; quiz 4-57.

36 Flicker L, Vasikaran SD, Thomas J, Acres JM, Norman $\mathrm{P}$, Jamrozik $\mathrm{K}$, et al. Efficacy of $B$ vitamins in lowering homocysteine in older men: maximal effects for those with B12 deficiency and hyperhomocysteinemia. Stroke 2006; 37: 547-9.

37 Jonsson $\mathrm{K}$. Using panel data to increase the power of modified unit root tests in the presence of structural breaks. Appl Math Comput 2005; 171: 832-42.

38 Group VTS. B vitamins in patients with recent transient ischaemic attack or stroke in the VITAmins TO Prevent Stroke (VITATOPS) trial: a randomised, double-blind, parallel, placebo-controlled trial. Lancet Neurol 2010; 9 : 855-65.

39 Brown RD, Langshaw MR, Uhr EJ, Gibson JN, Joshua DE. The impact of mandatory fortification of flour with folic acid on the blood folate levels of an Australian population. Med J Aust 2011; 194: 65-7.

40 Papakostas Gl, Petersen T, Mischoulon D, Ryan JL, Nierenberg AA, Bottiglieri T, et al. Serum folate, vitamin B12, and homocysteine in major depressive disorder, Part 1: predictors of clinical response in fluoxetine-resistant depression. J Clin Psychiatry 2004; 65: 1090-5.

\section{psychiatry} in music

\section{In a coma}

\section{Cyrus Abbasian}

The Los Angeles-based hard-rock band Guns $\mathrm{N}^{\prime}$ Roses released Use Your Illusion albums (I and II) at the height of their fame. Their lesser known but no less monstrous song Coma, from album I, has no chorus, is more than 10 minutes long and is in five distinct parts. It provides interesting insight about its writers, AxI Rose (lead vocalist) and Slash (lead guitarist), who struggled with mental illness and drug and alcohol misuse.

The song begins with four regular heartbeats before the bass, drums and guitars join following the heart rhythm. Throughout the song more heartbeats and beeps of an ECG machine are heard. The initial lyrics include 'kinda like it in a coma' and on two occasions a man yells 'get the crash cart!' Four minutes into the song AxI sings more blissfully; but then the drums beat rapidly, perhaps indicating ventricular tachycardia as the defibrillator is applied for the second time. Subsequent to again being 'zapped' the song becomes more melodramatic before turning sinister. A woman's voice is heard talking to Axl, in the second person, mainly with a derogatory content. In the final part there is a dreaded sense of destiny with lyrics that include 'gotta one way ticket to your suicide'.

Acute confusional state, or delirium, is not uncommon in patients who have been in comatose states. It can present with confusion and surreal fluctuating states of mind sequentially not dissimilar to the five parts of this song. These include being in and out of tranquil states, hallucinations and out of body experiences; the song makes four references to floating or sailing.

Axl Rose was diagnosed 'manic-depressive' and prescribed lithium. He started writing Coma after impulsively overdosing and being treated in hospital. Slash, in his autobiography, confesses to having used heroin, ecstasy and cocaine. He experienced drug-induced psychosis with episodes of acute paranoia, once running away naked from little versions of the aliens from the film Predator. Slash described the period 1999 to 2001 as his darkest, when 'I started drinking from first thing in the morning'. He was comatose with cardiomyopathy, at one stage was given 6 weeks to live, and eventually had a defibrillator implanted.

Axl and Slash are currently well and abstinent but have not spoken for years. 